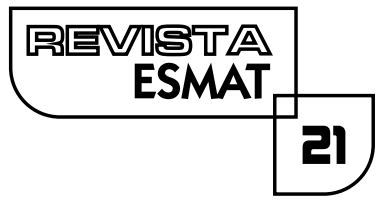

\title{
A ADOÇÃO DE POLÍTICAS PÚBLICAS PARA A DEMOCRATIZAÇÃO DO ENSINO SUPERIOR:UMA ANÁLISE ACERCA DA LEI DE RESPONSABILIDADE FISCAL
}

THE ADOPTION OF PUBLIC POLICIES FOR THE DEMOCRATIZATION OF HIGHER EDUCATION: AN ANALYSIS OF THE TAX RESPONSIBILITY LAW

Felipe Cesar José Matos Rebêlo

Mestre e doutor em Direito Político e Econômico, pela Universidade Presbiteriana Mackenzie, São Paulo. Pós-Doutorando em Democracia e Direitos Humanos, pela Universidade de Coimbra. Advogado e professor nos cursos lato sensu em Direito, pela Universidade Presbiteriana Mackenzie. Membro Efetivo da Comissão de Direitos Infanto-Juvenis da OAB/SP. E-mail: felipecesar375@gmail.com

\section{RESUMO}

Ensino Superior cumpre importância na sistematicidade constitucional brasileira, bem como na legislação infraconstitucional, mormente na lei de responsabilidade fiscal. Nesse sentido, os princípios constitucionais oponíveis ao tema merecem ser estudados, bem como as características basilares da lei de responsabilidade fiscal como norte para a intelecção da possibilidade de uma maior democratização no acesso ao Ensino Superior, respeitadas as determinantes citadas. Trata-se de indagar acerca da extensão de tais determinantes, e se estas encontram identificação com as demandas sociais, e com os requintes estruturais da democracia participativa que se alastram no decorrer das últimas três décadas, de forma incisiva, no caso brasileiro. Adota-se o método hipotético-dedutivo.

PALAVRAS-CHAVE: Ensino Superior. Lei de Responsabilidade Fiscal. Constituição Federal. Democracia Participativa.

\section{ABSTRACT}

University education is important in the Brazilian constitutional system, as well as in infraconstitutional legislation, especially in the fiscal responsibility law. In this sense, the constitutional principles opposable to the theme deserve to be studied, as well as the basic characteristics of the fiscal responsibility law as the north for the understanding of the possibility of a greater democratization in the access to University Education, respecting the mentioned determinants. It is necessary to inquire about the extent of these determinants, and whether they are identified with the 
social demands, and with the structural refinements of participatory democracy that have spread over the last three decades, incisively, in the Brazilian case. The hypothetical-deductive method is adopted.

KEYWORDS: University Education. Fiscal Responsibility Law. Federal Constitution. Participative Democracy.

\section{INTRODUÇÃO}

A democratização e seu processo subsequente de aprofundamento em suas nuances, sob uma perspectiva participativa, têm se demonstrado uma realidade oponível ao caso brasileiro nas últimas décadas.

Dentro dessa expressão, realiza-se a compreensão de que pode ser feita sobre um dos matizes mais essenciais de uma sociedade, e que também merece a acolhida quanto à sua situação democrática inclusiva, nos moldes retratados. Está-se a referir ao Ensino Superior, figura integrante do quadrante da educação nacional.

Diante da importância que o Ensino Superior assume para o País, com capacidade contributiva exponencial para o desenvolvimento e inclusão social, pensa-se acerca da normatividade oponível ao tema, em termos de facilitação da democratização, que se expressa por uma maior inclusão nesse processo de construção educacional.

Como recorte legal, portanto, aborda-se essa temática sob a perspectiva da Constituição Federal e da Lei de Responsabilidade Fiscal, como principais marcos legais referíveis ao tema.

Obviamente, destacam-se outros diplomas legislativos que podem ser incluídos na discussão, como a própria Lei de Diretrizes e Bases da Educação Nacional, mas esta pode receber uma acolhida paralela no presente trabalho, que irá perscrutar de forma mais incisiva como o detalhamento orçamentário nacional pode refletir na questão da democratização inclusiva no Ensino Superior.

Portanto, tem-se por objetivo averiguar como a legislação citada pode propiciar a facilitação pressuposta, de forma a se atender à democratização participativa exposta nos últimos anos na realidade factual. Alguns caminhos podem ser traçados sob essa perspectiva, de modo a se compreender a questão colocada. Pode se entender que o alargamento dos conceitos incrustados na Lei de Responsabilidade Fiscal pode sofrer certo prestígio no estudo formulado, em consonância aos princípios constitucionais, de maneira a propiciar um maior acesso democrático ao ensino universitário. Outrossim, pode se especular acerca da vedação a essa alternativa, e a construção de outras que possam propiciar mais inclusão democrática, mas ressalvados de forma incólume os preceitos da citada legislação infraconstitu- 
cional. A ponderação pode restar uma ferramenta oponível para a compreensão e consecução dos fins almejados no trabalho que aqui se apresenta.

Por fim, cumpre esclarecer que, para o alcance dos fins do trabalho, diz-se que o método de abordagem adotado é o hipotético-dedutivo, pois o trabalho intelectivo se baseia na apreciação da hipótese formulada, confrontando-se esta com o conhecimento existente, expresso pelas doutrinas nacional e internacional afeitas ao tema, e, em caráter complementar, pelo relacionamento desse conhecimento com os casos práticos vislumbráveis à temática e naquilo que for pertinente. De outra via, o método de procedimento adotado na pesquisa é o que se baseia pelo levantamento bibliográfico, expresso pelo método dissertativo-argumentativo, pois se pretende apresentar o tema com a devida profundidade, pautando-se pelas doutrinas nacional e internacional afeitas ao tema, pautando-se pelo estudo da realidade local e da realidade legislativa. Busca-se, com todo o proposto, a edificação do argumento sob apreciação das bases sólidas e cientificamente concatenadas.

\section{O ENSINO SUPERIOR E A CONSTITUIÇÃO FEDERAL}

A educação ocupa um espaço importante na Constituição Federal, de 1988.

Encontra abordagem expressa a partir do art. 206, sistematizando-se em princípios e regras concretas acerca de seus desdobramentos pelos entes federativos, quais sejam, a União, os Estados, o Distrito Federal e os Municípios.

Antes de tudo, assume a natureza de direito fundamental, com expressão de direito social (art. 6), cabendo ao Estado adotar as devidas políticas públicas para a sua concretização. É um direito fundamental, mas que assume tessitura diferenciada, relacionando-se aos postulados básicos de Constituição da República Federativa do Brasil, no que se refere à afirmação da dignidade da pessoa humana, conforme os ditames da justiça social. Com efeito, não se pode pensar em lograr alcançar tal fim, sem a devida oferta à sociedade da educação que lhe permita trilhar esse caminho.

De forma geral, a educação observa certos princípios, tais quais preconizados no art. 206 do documento constitucional:

Art. 206. O ensino será ministrado com base nos seguintes princípios:

I - igualdade de condições para o acesso e permanência na escola; II - liberdade de aprender, ensinar, pesquisar e divulgar o pensamento, a arte e o saber;

III - pluralismo de ideias e de concepções pedagógicas, e coexistência de instituições públicas e privadas de ensino; 
IV - gratuidade do ensino público em estabelecimentos oficiais; $\checkmark$ - valorização dos profissionais da educação escolar, garantidos, na forma da lei, planos de carreira, com ingresso exclusivamente por concurso público de provas e títulos, aos das redes públicas; $\mathrm{VI}$ - gestão democrática do ensino público, na forma da lei; VII - garantia de padrão de qualidade.

VIII - piso salarial profissional nacional para os profissionais da educação escolar pública, nos termos de lei federal.

IX - garantia do direito à educação e à aprendizagem ao longo da vida.

Parágrafo único. A lei disporá sobre as categorias de trabalhadores considerados profissionais da educação básica e sobre a fixação de prazo para a elaboração ou adequação de seus planos de carreira, no âmbito da União, dos Estados, do Distrito Federal e dos Municípios.

Deve ser esclarecido que alguns destes se revelam de aplicação mais consentânea ao ensino superior. A gratuidade pode ser aferida como mais próxima aos ensinos básico e médio, em que se revela um objetivo governamental a sua universalização. A autonomia universitária, por si, se revela um traço marcante do ensino superior, embora se encontre como prerrogativa a ser adaptada às demais formas de ensino.

A autonomia universitária se define como a possibilidade de direção própria, baseada em normatização superior e exercida por regras exclusivas (CEZNE, 2006, p. 124). Encontra limites na legislação ordinária, cabendo destacar os arts. 53 e 54 da Lei de Diretrizes e Bases da Educação Nacional (LDB) - Lei n 9.394, de 1996. Deve-se adaptar, outrossim, às limitações constitucionais, estipuladas da seguinte forma: autonomia didática, autonomia científica, autonomia administrativa e autonomia de gestão financeira e patrimonial.

A autonomia didática dedica-se à relevância do conhecimento e à forma de sua transmissão. A autonomia científica se associa à primeira, relacionando-se ao art. 206, inciso II, preconizando a faculdade de o professor pesquisar e ministrar conteúdo de acordo com aquilo que entende oponível como verdade no currículo. A autonomia administrativa, por sua vez, refere-se à auto-organização universitária, tendo-se a liberdade de estipular os meios cabíveis para o alcance de seus fins. É um instrumento para a autonomia didático-científica e pressuposto para a autonomia de gestão financeira e patrimonial. Esta, por último, pode ser compreendida como a capacidade de gerência de recursos, devendo haver uma alocação criteriosa destes, concretizando a responsabilidade institucional, que pode ser avaliada via prestação de contas, nos termos predispostos pelo art. $70 \mathrm{da}$ Constituição Federal, de 1988 (CEZNE, 2006, p. 124-125).

A Lei de Diretrizes e Bases da Educação Nacional contribui para a realização dos princípios constitucionais atinentes à educação, na medida do possível, não somente no que se refere à qualificação da autonomia, como também na estipulação 
das fontes de financiamento, ainda mais vitais para os ensinos infantil, fundamental e médio (SILVA, 2017, p. 127):

(...) concordamos que a LDBEN 9.394/96 possibilitou avanços no financiamento da educação, principalmente no que se refere à vinculação de recursos, porém, é evidente que os vinte anos da sua implementação foi e é permeada por desafios cotidianos, principalmente no que se refere à manutenção e à ampliação dos recursos financeiros. Concordamos que sem recursos não há como garantir os avanços previstos, principalmente no que se refere ao acesso a todas as modalidades, a equidade e a qualidade da educação para todos.

Por fim, cabe elucidar que, diferentemente dos ensinos básico e médio, não se aplica ao ensino superior a obrigatoriedade da gratuidade, nos termos dispostos pelo art. 213 do documento constitucional. Fala-se na necessidade de autofinanciamento das entidades privadas de ensino superior. O parágrafo único do dispositivo constitucional em comento traz uma advertência importante, que permite o financiamento a entidades privadas, não se adstringindo às universidades públicas. Trata-se da possibilidade de destinação de recursos públicos para atividades de pesquisa e extensão, não se limitando a entidades públicas de ensino, entidades comunitárias, confessionais e filantrópicas hábeis a tanto.

\section{O ENSINO SUPERIOR E A LEI DE RESPONSABILIDADE FISCAL}

A Lei de Responsabilidade Fiscal (Lei Complementar no I0 I, de 2000) pode ser considerada uma normatividade afeita à questão do desenvolvimento do Ensino Superior brasileiro, ainda mais devido à natureza jurídica das unidades universitárias.

Com efeito, delimitou-se a citada lei complementar como uma resposta legislativa ao processo comumente observado, no caso brasileiro, de deterioração das finanças públicas em detrimento do atendimento das necessidades sociais prementes, expressas pelos direitos catalogados na normatividade constitucional e infraconstitucional.

Acabou-se perpetrando, no caminho tracejado pela legislação, certa preocupação não somente com o controle orçamentário e fiscal, como também com a transparência dos gastos feitos pela Administração Pública direta e indireta, englobando União, Estados, Distrito Federal e Municípios. Visa-se à implementação de um processo de accountability nas contas públicas, portanto, com caráter duradouro, e não temporário. 
Espelha-se, por assim dizer, em um processo democrático (MOREIRA NETO, 200 I , p. 5), essencialmente participativo, engendrado com mais veemência a partir do século $X X \mid$, no caso brasileiro, como uma consolidação ainda mais efusiva do processo de redemocratização que se iniciou na década de 1980 do século passado. Por consequência lógica, assume a legislação pertinente um papel que procura incorporar as novas demandas da própria democracia em seu movimento volátil:

A Lei de Responsabilidade Fiscal é um código de conduta para os administradores públicos que passam a obedecer às normas e limites para administrar, prestando contas sobre quanto e de que maneira gastam os recursos da sociedade. Esta lei representa um importante instrumento de cidadania para o povo brasileiro, onde todos os cidadãos terão acesso às contas públicas, podendo manifestar abertamente sua opinião, com o objetivo de ajudar a garantir sua boa gestão (SIMÃO, 2004, p. 6).

Não se esgota nesses pontos o objetivo precípuo da legislação consignada, podendo-se, também, entender que a questão do controle financeiro pressupõe a assistência da sociedade com o fito de exigir do poder público e das instituições públicas de ensino superior o desempenho eficiente de suas funções, o que passa pela instrumentalização de mecanismos aptos a facilitar a avaliação pública de desempenho de acordo com as finalidades da instituição especificamente considerada (ARAGÃO, 200 I , p. 98-99). Refere-se a esse processo avaliativo como a própria consolidação e garantia da efetivação do direito à educação (JUNQUEIRA, 201 I, p. 94).

As universidades públicas, como integrantes da administração indireta (na qualidade de autarquias), acabam, também, se sujeitando aos efeitos aqui designados, bem como às principais estipulações objetivas da legislação retratada.

O art. 165, inciso II, do parágrafo 9०, e o art. 169 da Constituição Federal asseveram o estabelecimento de lei complementar como a diretriz básica orçamentária para a condução das atividades públicas de despesas, mormente no tocante à limitação nos gastos com pessoal.

Seguindo esse ínterim, a Lei de Responsabilidade Fiscal, precipuamente em seu art. 19, delimita que os gastos com pessoal devem se perfazer na alçada de $60 \%$ da receita corrente líquida, como uma forma de se estabelecer um controle responsável nas finanças. Trata-se de um dispositivo legal que busca a racionalização das despesas por entre as unidades federativas, destrinchando situações que almejam, em tom precípuo, a utilização apropriada das citadas despesas no tocante aos gastos salariais e afins.

Não se considera, para o último tópico levantado, que esse limite de $60 \%$ se refere, apenas, a gastos com as instituições públicas de ensino, de forma direta. Pelo contrário, abarca toda a universalidade da Administração Pública, direta e indi- 
reta, no âmbito de todos os entes federativos. Observável, pois, nesse ponto, uma questão importante para a perpetração e utilização de recursos de forma mais efetiva pelas universidades públicas. A partir deste momento, os recursos auferidos são apropriados por tais entidades, sem perder a sua natureza essencialmente pública, em que pese se tornarem bens institucionais (RANIERI, 1994, p. 130).

Um grande enfoque que deve ser atribuído à Lei de Responsabilidade Fiscal se refere ao equilíbrio das contas públicas primárias, ou seja, um equilíbrio que se almeja autossustentável, em que as operações de créditos não devem gozar de uma posição muito favorável no balanço, em benefício do não endividamento público. Em outros termos, diz-se que, embora não seja imperativo o limite legal proposto de 60\%, os princípios-base da Lei de Responsabilidade Fiscal (elencados em seu art. $1^{\circ}$ ), como o equilíbrio das contas e a obediência a limites legais, em coroamento ao princípio da legalidade, levam ao conhecimento de que os gastos dessas instituições não podem ocorrer fora das diretrizes legais e constitucionais mencionadas. Carlos Valder do Nascimento aborda essa temática de forma objetiva aos termos propostos no presente trabalho:

Os princípios básicos de gestão fiscal, que consubstanciam a responsabilidade das finanças públicas, configuram instrumentos essenciais à administração racional dos recursos financeiros postos à disposição do Poder Público. Permeando o atuar da União, Estados, Distrito Federal e Municípios, aos quais se vinculam na formação do sistema de responsabilidade fiscal montado pela lei complementar e constitucional e pelas resoluções do Senado Federal, tais princípios buscam embasar a atividade financeira estatal, imprimindo-lhe eficiência e operacionalidade. No plano jurídico, poder-se-iam eleger como princípios fundamentais da gestão fiscal: prevenção de déficits, prudência fiscal, segurança, planejamento e publicidade ou transparência. Os déficits fiscais, na visão clássica dos que se ocupam com o direito financeiro, têm sua inserção no orçamento público, corporificando o conteúdo receita e despesa, de cuja junção resultam os estudos e análises sobre o desempenho da gestão administrativa (NASCIMENTO, 2014, p. 57).

Nina Beatriz Stocco Ranieri (20 I5, p. 4I) pronuncia-se em sentido confluente ao exposto:

Não se pode perder de vista, porém, que as universidades estão submetidas aos princípios do art. lo. Logo, embora o limite de $60 \%$ não seja cogente, os princípios da LRF o são, e algum limite 
deve ser estabelecido. $\bigcirc$ equilíbrio entre receitas e despesas é mandatório.

A Jurisprudência do Supremo Tribunal Federal pode ser citada aprofundando a concepção detalhada pela doutrina relatada, mormente Nina Beatriz Stocco Ranieri:

Ação Direta de Inconstitucionalidade. AMB. Lei n | 4.506, de 16 de novembro de 2009, do Estado do Ceará. Fixação de limites de despesa com a folha de pagamento dos servidores estaduais do Poder Executivo, do Poder Legislativo, do Poder Judiciário e do Ministério Público estadual. Conhecimento parcial. Inconstitucionalidade. I. Singularidades do caso afastam, excepcionalmente, a aplicação da jurisprudência do Supremo Tribunal Federal sobre a prejudicialidade da ação, visto que houve impugnação em tempo adequado e a sua inclusão em pauta antes do exaurimento da eficácia da lei temporária impugnada, existindo a possibilidade de haver efeitos em curso (art. $7^{\circ}$ da Lei 14.506/2009). 2. Conquanto a $A M B$ tenha impugnado a integralidade da lei estadual, o diploma limita a execução orçamentária não apenas em relação aos órgãos do Poder Judiciário, mas também em relação aos Poderes Executivo e Legislativo e do Ministério Público, os quais são alheios à sua atividade de representação. Todos os fundamentos apresentados pela requerente para demonstrar a suposta inconstitucionalidade restringem-se ao Poder Judiciário, não alcançando os demais destinatários. Conhecimento parcial da ação. 3. Conforme recente entendimento firmado por esta Corte, "[a] lei não precisa de densidade normativa para se expor ao controle abstrato de constitucionalidade, devido a que se trata de ato de aplicação primária da Constituição. Para esse tipo de controle, exige-se densidade normativa apenas para 0 ato de natureza infralegal" (ADI 4.049/DF-MC, Relator o Ministro Ayres Britto, DJ de 8/5/09). Outros precedentes: ADI 4.048/DF-MC, Relator Ministro Gilmar Mendes, DJ de 22/8/08; ADI 3.949/DF-MC, Relator Ministro Gilmar Mendes, DJ de 7/8/09). Preliminar de não conhecimento rejeitada. 4. Apenas 0 art. $2^{\circ}$ da lei impugnada coincide com o disposto na lei de diretrizes orçamentárias. Essa semelhança, contudo, não impede, por si só, o conhecimento da ação, uma vez que a Lei de Diretrizes Orçamentárias, em tese, não conteria os mesmos vícios apontados pela $A M B$, pois contou com a participação do Poder Judiciário na sua elaboração. $\quad$ 5. A expressão "não poderá exceder", presente no artigo 169 da Constituição Federal, conjugada com o caráter nacional da lei complementar ali mencionada, assentam a noção de marco negativo imposto a todos os membros da Federação, no sentido de que os parâmetros de controle de gastos ali estabelecidos não podem ser ultrapassados, sob pena de se atentar contra o intuito de preservação do equilíbrio orçamentário (receita/des- 
pesa) consagrado na norma. $\quad$ 6. O diploma normativo versa sobre execução orçamentária, impondo limites especialmente às despesas não previstas na folha normal de pessoal. Tais limites, conquanto não estejam disciplinados na lei de diretrizes orçamentárias e na lei orçamentária anual, buscam controlar a forma de gestão dos recursos orçamentários já aprovados. A participação necessária do Poder Judiciário na construção do pertinente diploma orçamentário diretivo, em conjugação com os outros Poderes instituídos, é reflexo do status constitucional da autonomia e da independência que lhe são atribuídas no artigo $2^{\circ}$ do Diploma Maior. Esse é o entendimento que decorre diretamente do conteúdo do art. 99, $\S 1^{\circ}$, da Constituição Federal. 7. A autonomia financeira não se exaure na simples elaboração da proposta orçamentária, sendo consagrada, inclusive, na execução concreta do orçamento e na utilização das dotações postas em favor do Poder Judiciário. O diploma impugnado, ao restringir a execução orçamentária do Judiciário local, é formalmente inconstitucional, em razão da ausência de participação desse na elaboração do diploma legislativo. 8. Ação direta de inconstitucionalidade julgada parcialmente procedente para declarar, com efeitos extunc, a inconstitucionalidade da expressão "e Judiciário" contida nos arts. $1^{\circ}$ e $6^{\circ}$ da lei impugnada e para declarar a inconstitucionalidade parcial sem redução de texto dos demais dispositivos da Lei n $n^{\circ}$ 4.506/09 do Estado do Ceará, afastando do seu âmbito de incidência o Poder Judiciário (grifo nosso) (STF - Ação Direta de Inconstitucionalidade n. 4.426, Plenário - Rel. Min. Dias Toffoli - j. 09.02.20II, DJE 18.5.201 I).

Diante da questão da democratização do ensino superior e acerca de uma das facetas que vem assumindo o próprio ensino universitário hodiernamente, no concernente ao seu caráter de autonomia, se perscruta acerca da aplicabilidade da Lei de Responsabilidade Fiscal nos termos estritos propostos por seus ditames. As amarras da normatividade mencionada têm inspirado comportamentos diversos por parte das instituições de ensino:

(...) antes da LRF muitos municípios que atendiam diretamente a educação já gastavam $60 \%$ ou mais dos recursos orçamentários em folha de pessoal. Com a LRF, para que os dirigentes pudessem garantir essa obrigação legal e até mesmo ampliar o atendimento, a alternativa encontrada foi a terceirização dos serviços de limpeza, segurança, apoio administrativo, não realização de concurso público de títulos e provas para a admissão de pessoal, congelamento da remuneração dos profissionais da educação e em alguns casos, a transferência da educação de jovens e adultos e a educação infantil para grupos filantrópicos, comunitários e ONGs, sob o discurso de que a folha de pagamento não poderia 
ultrapassar a 60\%, o que não contribuiu para a melhoria da qualidade da educação (SILVA, 20 I7, p. |24- |25)

Pergunta-se, por consequência, se em cotejo à autonomia universitária e a outros elementos auxiliares que podem ser vislumbrados para a perpetuação de um maior acesso democrático ao ensino superior, como construção discutida pela sociedade e como produto de acesso aos integrantes desta (pela inserção de instrumentos fiscais facilitadores na própria normatividade pertinente), se a responsabilidade fiscal merece a acolhida como um princípio estanque, que não comporta flexibilizações para o alcance do mister proposto, ou se sua aplicabilidade deve realçar um compartimento de núcleo duro e mais responsivo.

O próximo item do presente trabalho tratará com mais assiduidade essas temáticas suscitadas.

\section{POLÍTICAS PÚBLICAS E ALARGAMENTO DO CONCEITO DA LEI DE RESPONSABILIDADE FISCAL: A AUTONOMIA UNIVER- SITÁRIA E OUTRAS ALTERNATIVAS}

Fala-se acerca do alargamento do alcance da Lei de Responsabilidade Fiscal para a sua mais aprimorada intelecção. Diante da avaliação que o Supremo Tribunal Federal apresenta sobre a temática, cabe uma avaliação de hipóteses que possibilitem a maior inserção de indivíduos nas universidades, bem como o devido financiamento para tanto.

Deve-se ter em mente que, inicialmente, investimentos foram feitos ao decorrer dos anos 1990 para o alastramento do ensino superior, e sob a égide do Governo Fernando Henrique Cardoso. O Governo Lula promoveu a manutenção desse investimento, na esteira de se garantir a uma necessidade do mercado. A necessidade da maior qualificação profissional, acoplada a pressões populares internas, referendou o investimento perpetrado, em que pese sua recaída nos últimos anos, mormente a partir do Governo Dilma Rousseff.

As Instituições Federais de Ensino Superior (IFES), em que pese à autonomia universitária como um de seus principais braços de atuação, observam uma grande dependência de recursos federais. Ao início da primeira década dos anos 2000, mais de $80 \%$ dos repasses totalizados pela União encaminhavam-se para os gastos com pessoal e funcionários (SANTOS, 20।3), situação que não encontrou muita alternância nos dias correntes. As Instituições Federais de Ensino Superior, assim como as instituições estaduais de ensino superior, apresentam um papel fundamental para a pesquisa e à inovação, contribuindo para o florescimento de trabalhos científicos e pesquisas que fornecem novas utilidades para todas as searas do campo econômico, desde o campo petrolífero até o desenvolvimento de novos medicamentos. 
Tabela I - Recursos liberados pelo MEC para as Universidades Federais - 10 primeiras instituições com maior acréscimo orçamentário (2019)

\begin{tabular}{|c|c|c|c|c|}
\hline Universidade & $\begin{array}{l}\text { Recurso Ca- } \\
\text { pital }\end{array}$ & $\begin{array}{l}\text { Valor Distribuí- } \\
\text { do }\end{array}$ & $\begin{array}{l}\text { Valor de } \\
\text { Acréscimo }\end{array}$ & $\begin{array}{l}\text { Percentual } \\
\text { de Acrés- } \\
\text { cimo }\end{array}$ \\
\hline $\begin{array}{l}\text { Universidade } \\
\text { Federal Rural } \\
\text { da Amazônia }\end{array}$ & $\mathrm{R} \$ 828.824$ & $R \$ 2.418 .965$ & $\mathrm{R} \$ 3.247 .789$ & $292 \%$ \\
\hline $\begin{array}{l}\text { F u n d a ç ã o } \\
\text { Universidade } \\
\text { Federal de } \\
\text { São Carlos }\end{array}$ & $\mathrm{R} \$ 1.259 .043$ & $R \$ 1.995 .646$ & $R \$ 3.254 .689$ & $159 \%$ \\
\hline $\begin{array}{l}\text { Fu n d a çã o } \\
\text { Universidade } \\
\text { Federal do } \\
\text { ABC }\end{array}$ & $\mathrm{R} \$ 1.926 .563$ & $R \$ 3.023 .706$ & $R \$ 4.950 .269$ & | 57\% \\
\hline $\begin{array}{l}\text { Universidade } \\
\text { Federal do } \\
\text { Rio Grande } \\
\text { do Sul }\end{array}$ & $\mathrm{R} \$ 1.483 .352$ & $R \$ 2.177 .068$ & $R \$ 3.660 .420$ & 147\% \\
\hline $\begin{array}{l}\text { Universidade } \\
\text { da Integração } \\
\text { Internacional } \\
\text { da Lusofonia } \\
\text { Afro-brasileira }\end{array}$ & $R \$ 1.000 .000$ & $\mathrm{R} \$ 1.451 .379$ & $\mathrm{R} \$ 2.451 .379$ & | $45 \%$ \\
\hline $\begin{array}{l}\text { Fu n d a çã o } \\
\text { Universidade } \\
\text { Federal de } \\
\text { Ouro Preto }\end{array}$ & $\mathrm{R} \$ 1.862 .306$ & $\mathrm{R} \$ 2.418 .965$ & $\mathrm{R} \$ 4.28 \mathrm{I} .27 \mathrm{I}$ & $130 \%$ \\
\hline $\begin{array}{l}\text { F u n d a çã o } \\
\text { Universidade } \\
\text { Federal do } \\
\text { Vale do Rio } \\
\text { São Francisco }\end{array}$ & $\mathrm{R} \$ 1.628 .029$ & $R \$ 2.056 .120$ & $R \$ 3.684 .149$ & $126 \%$ \\
\hline
\end{tabular}




\begin{tabular}{|c|c|c|c|c|}
\hline $\begin{array}{l}\text { Universidade } \\
\text { Federal dos } \\
\text { Vales do Je- } \\
\text { quitinhonha e } \\
\text { Mucuri }\end{array}$ & $\mathrm{R} \$ 1.522 .56 \mid$ & $\mathrm{R} \$ 1.8 \mid 4.224$ & $R \$ 3.336 .785$ & $119 \%$ \\
\hline $\begin{array}{l}\text { F u n d a ç ã o } \\
\text { Universidade } \\
\text { Federal da } \\
\text { Grande Dou- } \\
\text { rados }\end{array}$ & $R \$ 1.538 .257$ & $\mathrm{R} \$ 1.814 .224$ & $\mathrm{R} \$ 3.352 .481$ & | | $8 \%$ \\
\hline $\begin{array}{l}\text { Fu n d a çã o } \\
\text { Universidade } \\
\text { Federal de } \\
\text { Rondônia }\end{array}$ & $\begin{array}{l}R \\
1.800 .000\end{array}$ & $R \$ 2.056 .120$ & $\begin{array}{l}R \\
3.856 .120\end{array}$ & $114 \%$ \\
\hline
\end{tabular}

Fonte: Ministério da Educação

Em virtude da importância apresentada para a concretização do tripé pesquisa-ensino-extensão, e tendo-se em mente paralelamente a necessidade de inclusão social, as instituições de ensino superior precisam recorrer de forma veemente a alternativas para manter seu funcionamento, não obstante os repasses federais, que, segundo o Ministério da Educação, cresceram até o ano de 2019, apesar das projeções de decréscimos no orçamento pelas universidades federais (o governo federal anunciou o corte de $\mathrm{R} \$$ I,4 bilhão do orçamento de universidades e institutos federais em 202 I), como é a situação do Instituto Federal do Rio Grande do Sul (IFRS) - exemplo de várias instituições públicas de ensino e pesquisa que se encontram na mesma situação. A promoção de cursos de extensão, oferecimento de oficinas para o aprimoramento técnico, dentre outras medidas, são empreendidas por essas instituições com o foco de se obter o devido arcabouço financeiro que sustente devidamente suas atividades. Dessa forma, o risco de captação por financiadores privados se revela algo presente, uma vez que estes continuam investindo nessas instituiç̧̃̃es'.

Nessa esteira, cabe asseverar que as instituições públicas de ensino com altos padrões de pesquisa e de ensino foram aquelas que adotaram uma posição pela valorização da dedicação exclusiva e pesquisa básica, mantendo um grau elevado de independência em referência às influências nefastas do mercado. Tal realida-

I No caso brasileiro, segundo dados apresentados pela Confederação Nacional da Indústria e o Ministério da Ciência, Tecnologia e Inovação, em 2010 cerca de 50\% do investimento na área era feito pelo setor público, cabendo o restante ao setor privado, percentagens que mantiveram essa média nos últimos anos. 
de tem se perpetrado mesmo com as pressões externas (LEOPOLDO E SILVA, 2001, p. 299).

Tabela 2 - Queda do orçamento das Universidades. Caso do Instituto Federal do Rio Grande do Sul (IFRS)

\begin{tabular}{|c|c|c|c|c|c|c|}
\hline Ano & $\begin{array}{l}\text { Orça- } \\
\text { mento } \\
\text { Custeio } \\
\text { ( e m } \\
R \$ \text { mi- } \\
\text { lhões) }\end{array}$ & $\begin{array}{l}\text { Orça- } \\
\text { m en to } \\
\text { Investi- } \\
\text { mento } \\
\text { (em R\$ } \\
\text { milhões) }\end{array}$ & $\begin{array}{l}\text { Orça - } \\
\text { m e n t o } \\
\text { Assistên- } \\
\text { cia Es- } \\
\text { tudantil } \\
\text { (em R\$ } \\
\text { milhões) }\end{array}$ & $\begin{array}{l}\text { Custeio } \\
+ \text { Inves- } \\
\text { timento } \\
\text { (em R\$ } \\
\text { milhões) }\end{array}$ & $\begin{array}{l}\text { Total (em } \\
\mathrm{R} \$ \text { mi- } \\
\text { lhões) }\end{array}$ & $\begin{array}{l}\text { Estudantes } \\
\text { Matricu- } \\
\text { lados em } \\
\text { Cursos Re- } \\
\text { gulares }\end{array}$ \\
\hline 2015 & 42,56 & 36,56 & 10,29 & 79,12 & 89,41 & 17.790 \\
\hline 2016 & 45,23 & 12,29 & 10,22 & 57,52 & 67,74 & 20.517 \\
\hline 2017 & 45,60 & 3,89 & 10,30 & 49,49 & 59,79 & 21.352 \\
\hline 2018 & 43,24 & 3,50 & 11,16 & 46,74 & 57,90 & 21.008 \\
\hline 2019 & 43,41 & 5,44 & 12,97 & 48,85 & 61,82 & 21.859 \\
\hline 2020 & 41,97 & 5,26 & 12,53 & 47,23 & 59,76 & 23.082 \\
\hline$\left.202\right|^{*}$ & 36,58 & 1,20 & 10,35 & 37,78 & 48,13 & 24.305 \\
\hline
\end{tabular}

*Projeção

Fonte: IFRS

Os Governos Fernando Henrique Cardoso e Lula centraram os investimentos públicos, com vista à obtenção da inclusão social, por programas como o Programa Universidade para Todos (PROUNI), e o Programa de Apoio a Planos de Reestruturação e Expansão das Universidades Federais (REUNI), ampliando-se as vagas para pessoas de menor poder aquisitivo, extensão da oferta dos cursos de graduação, extensão da oferta dos cursos noturnos, combate à evasão e inclusão da oferta de moradia para os estudantes mais pobres (PRESTES; JEZINE; SCOCUGLIA, 20I2). Em virtude desse cenário, de acordo com dados colhidos pelo INEP e IBGE, encontra-se um alcance maior do ensino superior na sociedade (ver Tabela 3 e Gráficos), o que faz repensar se as medidas extras adotadas pelas universidades são suficientes para o cumprimento de sua função social, ou se os limites impostos para investimento pela Lei de Responsabilidade Fiscal podem ser flexibilizados com o fulcro de se atender ao direito fundamental de acesso à educação. 
Tabela 3 - Números de concluintes e matrículas nos cursos de graduação presencial e à distância, segundo as regiões geográficas - Instituições Federais de Ensino Superior (2018)

\begin{tabular}{|l|l|l|l|l|}
\hline & $\begin{array}{l}\text { Concluintes } \\
\text { (graduação } \\
\text { presencial) }\end{array}$ & $\begin{array}{l}\text { Concluintes } \\
\text { (graduação à } \\
\text { distância) }\end{array}$ & $\begin{array}{l}\text { Matrículas } \\
\text { (graduação o } \\
\text { presencial) }\end{array}$ & $\begin{array}{l}\text { Matrículas } \\
\text { (graduação à } \\
\text { distância) }\end{array}$ \\
\hline Norte & 18.574 & 564 & 144.868 & 6.855 \\
\hline Nordeste & 40.165 & 5.080 & 376.830 & 33.506 \\
\hline Sudeste & 46.979 & 3.839 & 372.554 & 38.238 \\
\hline Sul & 24.721 & 706 & 209.820 & 8.550 \\
\hline $\begin{array}{l}\text { Centro } \\
\text {-Oeste }\end{array}$ & 15.434 & 856 & 127.837 & 5.926 \\
\hline Brasil & 145.873 & 11.045 & 1.231 .909 & 93.075 \\
\hline
\end{tabular}

Fonte: INEP 
Gráficos - Números de estudantes, por Grandes Regiões, no Ensino Superior Público Federal (20I2-20 I5)

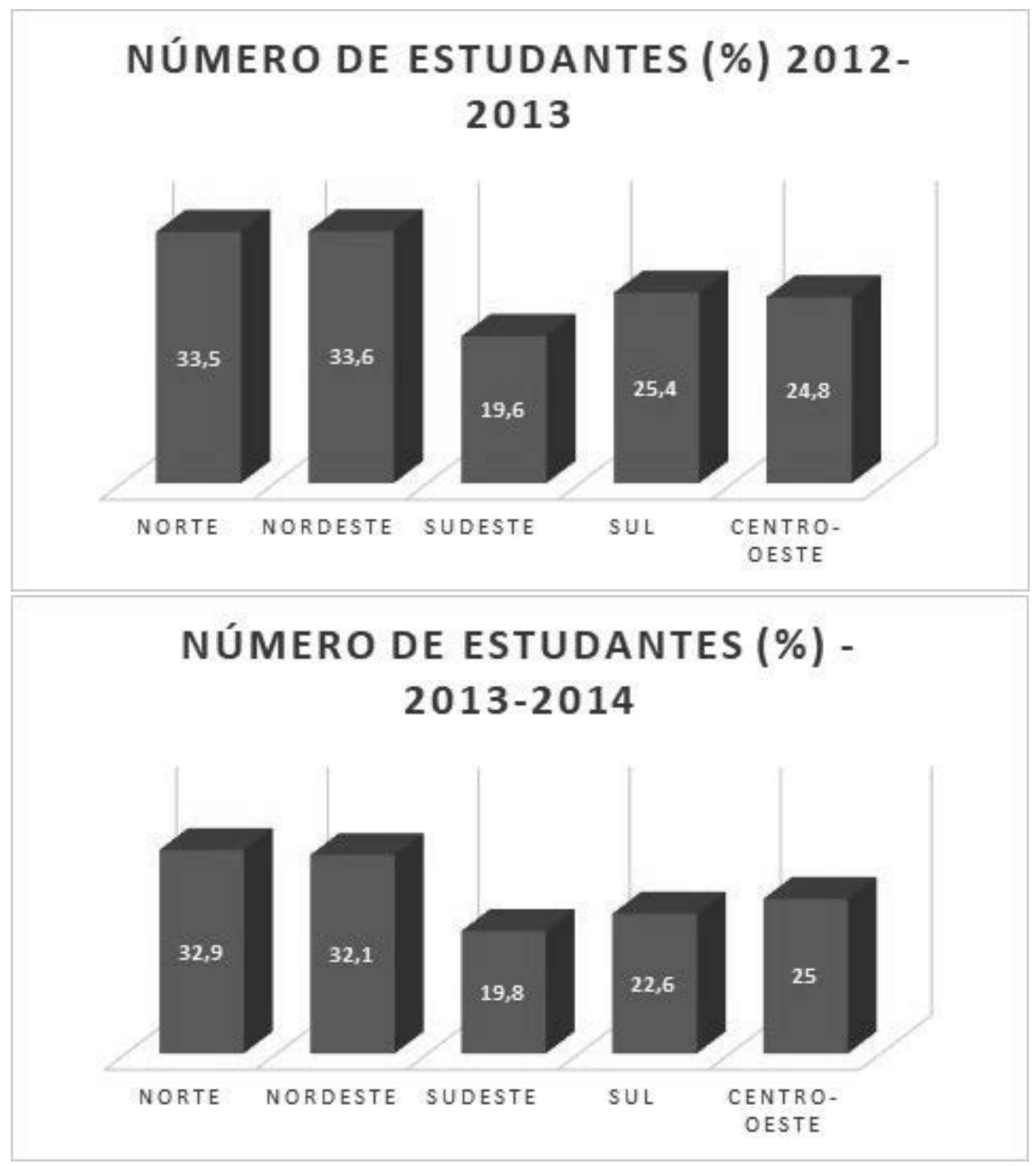




\section{NÚMERO DE ESTUDANTES (\%) 2014 - 2015}

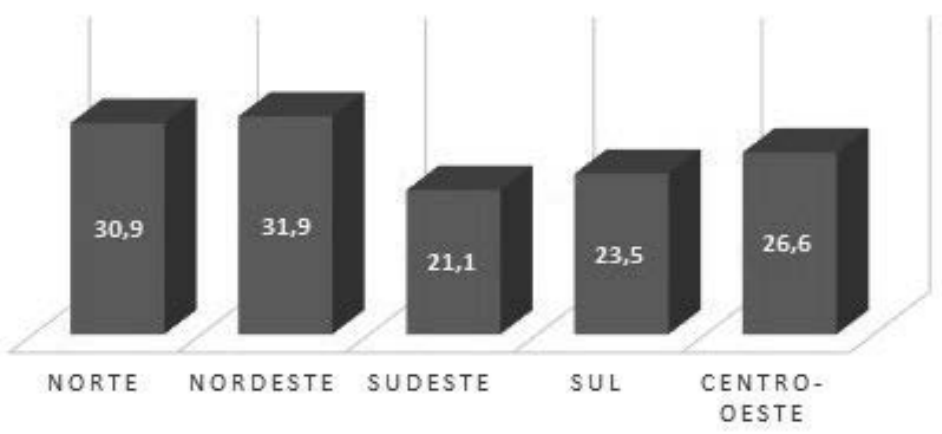

Fonte: IBGE. Gráficos feitos pela autoria

Quanto ao último enunciado, deve-se enfocar o implemento do Novo Regime Fiscal, promovido pela Emenda Constitucional no 95, que promove o congelamento das despesas primárias (o que engloba gastos com a educação e consolidação efetiva dos direitos sociais), reservando-se intacto o pagamento de dívidas, o que atende aos interesses do setor financeiro (ANDREA; GUNDIM, 2020). Em virtude dessa realidade, o Plano Nacional de Educação (PNE), 20।4-2024, fica comprometido quanto a suas metas, o que presume que a educação pública superior poderá não atingir seus objetivos nesse período. A ocorrência de pandemia, em 2020, parece prejudicar ainda mais essa realidade. Assim, os 10\% do PIB que deveriam, inicialmente, ser dirigidos para a educação, não encontrarão a destinação em sua integralidade (AMARAL, 2017, p. 19).

Pode-se afirmar, portanto, que, analisando a evolução dos recursos financeiros associados ao MEC nos anos de 2014, 2015, 2016 e 2017 — quatro anos dos dez anos do PNE (2014-2024) -, a possibilidade do cumprimento do conjunto de suas metas é muito remota, uma vez que os valores financeiros não foram reajustados por percentuais nem iguais à inflação medida pelo IPCA nos anos de 2015 e 2016 e, no ano de 2017, a LOA 2017 também não previu recursos financeiros que propiciassem o desenvolvimento de ações que objetivassem a execução das metas do PNE (20 | 4-2024). 
Tabela 4 - Organismos do Poder Executivo: diferença entre a variação anual e a inflação nos anos de 2016 e 2017, constantes das Leis Orçamentárias Anuais, em pontos percentuais

\begin{tabular}{|c|c|c|c|c|}
\hline $\begin{array}{l}\text { Organismos do } \\
\text { Poder Executivo } \\
\text { (estrutura cria- } \\
\text { da pela Lei } n^{\circ} \\
\text { 13.341, de 2016) }\end{array}$ & $\begin{array}{l}\text { Valores Correntes } \\
\text { Em Bilhões (LOA } \\
2016 \text { e LOA 2017, } \\
\text { respectivamente) }\end{array}$ & $\begin{array}{l}\text { Varia- } \\
\text { ção no } \\
\text { Período } \\
(\%)(a)\end{array}$ & 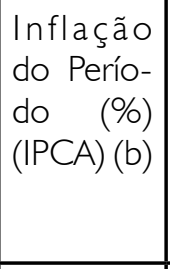 & $\begin{array}{l}\text { Diferença en- } \\
\text { tre a Variação } \\
\text { do Período e } \\
\text { a Inflação em } \\
\text { Pontos Per- } \\
\text { centuais (a-b) }\end{array}$ \\
\hline $\begin{array}{l}\text { Presidência da Re- } \\
\text { pública }\end{array}$ & 2,6 e 6,8 & $|6|, 54$ & $\mid 1,1$ & 150,44 \\
\hline $\begin{array}{l}\text { Ministério da Agri- } \\
\text { cultura, Pecuária e } \\
\text { Abastecimento }\end{array}$ & 12,8 e 12,3 & $(3,91)$ & $\mid 1,1$ & $-|5,0|$ \\
\hline $\begin{array}{l}\text { Ministério do } \\
\text { Meio Ambiente }\end{array}$ & 3,1 e 3,9 & 25,81 & $\mid 1,1$ & $|4,7|$ \\
\hline $\begin{array}{l}\text { Ministério da Edu- } \\
\text { cação }\end{array}$ & 106,0 e 107,3 & 1,23 & 11,1 & $-9,87$ \\
\hline $\begin{array}{l}\text { Ministério da Cul- } \\
\text { tura }\end{array}$ & 2,6 e 2,7 & 3,85 & $\mid 1,1$ & $-7,25$ \\
\hline $\begin{array}{l}\text { Ministério do Es- } \\
\text { porte }\end{array}$ & I,7 e I,5 & $(\mid I, 76)$ & $\mid 1,1$ & $-22,86$ \\
\hline $\begin{array}{l}\text { Ministério da Saú- } \\
\text { de }\end{array}$ & 120,9 e 125,4 & 3,72 & 11,1 & $-7,38$ \\
\hline $\begin{array}{l}\text { Ministério do De- } \\
\text { senvolvimento So- } \\
\text { cial e Agrário }\end{array}$ & 694,2 e 743,2 & 7,06 & $\mid 1,1$ & $-4,04$ \\
\hline $\begin{array}{l}\text { Ministério da } \\
\text { Ciência, Tecnolo- } \\
\text { gia, Inovações e } \\
\text { Comunicações }\end{array}$ & 15,9 e 15,6 & $(1,89)$ & $\mid 1,1$ & $-12,99$ \\
\hline $\begin{array}{l}\text { Ministério da Fa- } \\
\text { zenda }\end{array}$ & 26,5 e 25,3 & $(4,53)$ & $|1|$, & $-15,63$ \\
\hline
\end{tabular}




\begin{tabular}{|c|c|c|c|c|}
\hline $\begin{array}{l}\text { Ministério da In- } \\
\text { dústria, Comércio } \\
\text { Exterior e Serviços }\end{array}$ & 3,0 e 2,7 & $(10,00)$ & $|1|$, & $-21,10$ \\
\hline $\begin{array}{l}\text { Ministério da Jus- } \\
\text { tiça }\end{array}$ & | 5,7 e |4,2 & $(9,79)$ & $|1|$, & $-20,89$ \\
\hline $\begin{array}{l}\text { Ministério das Mi- } \\
\text { nas e Energia }\end{array}$ & 8,3 e 4,0 & $(5|, 8|)$ & $\mid 1,1$ & $-62,91$ \\
\hline $\begin{array}{l}\text { Ministério das Re- } \\
\text { lações Exteriores }\end{array}$ & 3,6 e 3,6 & - & $|1|$, & $-11,10$ \\
\hline $\begin{array}{lr}\text { Ministério } & \text { dos } \\
\text { Transportes, } & \text { Por- } \\
\text { tos e Aviação } & \text { Civil } \\
\end{array}$ & 34,2 e 27,6 & $(19,30)$ & $|1|$, & $-30,40$ \\
\hline $\begin{array}{l}\text { Ministério do Pla- } \\
\text { nejamento, De- } \\
\text { senvolvimento e } \\
\text { Gestão }\end{array}$ & 6,2 e 8,0 & 29,03 & $|1|$, & 17,93 \\
\hline $\begin{array}{l}\text { Ministério da De- } \\
\text { fesa }\end{array}$ & 86,4 e 94,7 & 9,61 & $|1|$, & $-1,49$ \\
\hline $\begin{array}{l}\text { Ministério da Inte- } \\
\text { gração Nacional }\end{array}$ & 7,8 e 7,2 & $(7,69)$ & $|1|$, & $-18,79$ \\
\hline $\begin{array}{l}\text { Ministério das Ci- } \\
\text { dades }\end{array}$ & $|3$,$| e 16,0$ & 22,14 & $|I|$, & 11,04 \\
\hline $\begin{array}{l}\text { Ministério do Tu- } \\
\text { rismo }\end{array}$ & I , I e 0,77 & $(30,00)$ & $\mid 1,1$ & $-41,10$ \\
\hline
\end{tabular}

Fonte: AMARAL (2017)

Fala-se, assim sendo, no papel de o Estado ser um agente em busca não da concreção do documento constitucional, mas de seu contrário, e com respaldo pela atividade do controle de constitucionalidade da Corte Suprema (DUTRA; FREITAS, 2019, p. 166-167):

(...) podemos afirmar que o próprio estado é o agente inconstitucional, ou seja, o próprio órgão responsável pela inconstitucionalidade no contexto da EC 95. Tendo em vista a circunstância de se aprovar esta medida, é notório considerar que a educação e o aumento de seus recursos não é evidenciada como prioridade. Assim, concordamos com Gonçalves (20l8) quando ele afirma que mesmo que a EC 95 não exclua totalmente o financiamento da saúde e educação, é possível constatar que os padrões míni- 
mos desses direitos a sociedade são, em comum, abaixo das expectativas. Além disso, ele destaca que a contenção de recursos acarretará em um risco maior de precarização, e não da eficácia da gestão pública. Tomando como base essa discussão, corroboramos com as considerações de Gonçalves (2018) quando ele sinaliza que não podemos apontar a certeza da efetividade da Emenda Constitucional 95. Não há indícios de um quadro de sucesso que vislumbre sanar a dívida pública do nosso país, o que existe, são apontamentos de um cenário de redução de gastos públicos e seus impactos desastrosos nas áreas sociais.

Presentes as circunstâncias mencionadas, cabe elucidar que, diante da própria visão que o Supremo Tribunal Federal tem sobre a aplicabilidade específica da Lei de Responsabilidade Fiscal, bem como da situação orçamentária do Estado brasileiro, é de difícil percepção que a normatividade citada possa encontrar flexibilização, mesmo que isso represente inconstitucionalidade, já que não se permite a eficácia a direito fundamental com base no binômio reserva do possível-mínimo existencial. $\bigcirc$ art. $5^{\circ}$, parágrafo $1^{\circ}$, da Constituição Federal acaba sendo atingido no exame da questão, em que pese à posição aquiescente da Corte Suprema brasileira.

Para a possível correção de distorções, fala-se em dois caminhos. $\bigcirc$ primeiro propugna pela adoção de políticas públicas acessórias aos programas nacionais previstos para a inclusão social nas universidades, e com qualidade de performance aos estudantes no curso superior, e sem se reservar quotas às elites investidas (BORTOLANZA, 2017). Sob essa esteira, a atuação dos entes federativos pode ser associada, buscando auxiliar a facilitação financeira àqueles desejosos de cursar o ensino superior público.

Em um segundo plano, fala-se do exemplo proporcionado pela Universidade Federal da Paraíba (PRESTES; JEZINE; SCOCUGLIA, 20I2). Esta instituição de ensino, sofrendo as mesmas dificuldades das demais, obteve verbas adicionais do Tesouro para a realização de programas pontuais, com vista a exercer suas atividades com a maior inclusão possível e, de outra monta, recorreu à iniciativa privada como apoio para tanto. Os cursos oferecidos dobraram entre 2009 e 2010 , passando de 465 para 775 alunos envolvidos. Outrossim, cabe destaque para o Programa de Bolsas de Extensão, com aumento de $27 \%$ de alunos agraciados no mesmo período, bem como os programas institucionais que objetivavam a melhoria da qualidade pedagógica, como o Programa de Consolidação das Licenciaturas (PRODOCÊNCIA), o Programa Institucional de Bolsas de Iniciação à Docência (PIBID) e o Programa de Projetos de Pesquisa na Licenciatura (PROLICEN), contribuintes da redação da evasão e retenção nos respectivos cursos de graduação (UNIVERSIDADE FEDERAL DA PARAÍBA, 20I0).

$\bigcirc$ resultado disso forma dados positivos apresentados pela Universidade, como se depreende a seguir: 
(...) uma política de expansão institucional, que objetiva a democratização do acesso não se pode realizar-se e sustentar-se sem haver uma disponibilidade financeira que garanta o ensino, a pesquisa e a extensão o intercâmbio com a sociedade e a possibilidade de agregar grupos diferenciados de estudantes na produção do conhecimento. Para propiciar essa expansão, do ano de 2004 até 2010 , a receita orçamentária da UFPB cresceu em 61,2\%, havendo um incremento em mais de $80,9 \%$, como se observa no quadro que segue. Parte desses recursos destinada a UFPB, segundo Souza Junior (20 I I:9), proveio da receita orçamentária do Tesouro, além de outras fontes públicas e privadas, oriundas de emendas parlamentares ao Orçamento Geral da União e de convênios com bancos públicos e privados que atuam no interior do campus I, em João Pessoa. Deste crescimento orçamentário é possível inferir que a política de expansão do ensino superior, via o setor privado, que atingiu as universidades públicas nos finais da década de 1990, no contexto de reforma do Estado brasileiro, e estimulou a redução do quadro docente e de funcionários, bem como a redução orçamentária da união tenha chegado ao fim com o REUNI, pois possibilitou às universidades públicas federais reestruturações importantes relacionadas à política expansionistas de natureza democrática (PRESTES; JEZINE; SCOCUGLIA, 20|2, p. 2|3-2|4).

A Lei de Diretrizes e Bases da Educação Nacional, ainda expressa certos caminhos alternativos. O primeiro prevê a possibilidade do aumento do percentual de recursos vinculados à educação:

Ainda sobre a vinculação de recursos, a LDBEN $9.394 / 96$ possibilita $\mathrm{O}$ aumento do percentual de recursos vinculados à educação, pois prevê que municípios, estados e distrito federal possam aumentar os índices vinculados conforme Constituições Estaduais e Leis Orgânicas, reconhecendo a possibilidade e necessidade de aumento do percentual mínimo estabelecido na CF/88. Desta forma, o percentual vinculado na LDBEN 9.394/96 é mínimo e não máximo, e possibilita que estados, distrito federal e municípios aumentem os investimentos para atender às necessidades educacionais da população (SILVA, 2017, p. 124).

Por fim, ainda se comenta acerca da ação supletiva e redistributiva de recursos pela União, adquirindo um caráter compensatório essa atividade:

Concomitante à vinculação dos recursos, a LDBEN 9.394/96 define a ação supletiva e redistributiva da União e estabelece no caput do art. 75 que esta e também dos estados deverá corrigir as disparidades de acesso e garantir o padrão mínimo de qualidade. Atualmente a ação redistributiva tem se pautado nas políticas de fundos de natureza contábil, a princípio pelo Fundo de Manu- 
tenção e Desenvolvimento do Ensino Fundamental e de Valorização do Magistério (FUNDEF) com vigência de 1996 a 2006 e posteriormente pelo Fundo de Manutenção de Desenvolvimento da Educação Básica e Valorização dos Profissionais da Educação (FUNDEB) com vigência de 2006 até o final de 2020 (SILVA, 2017, p. 125).

Verifica-se, portanto, que a autonomia universitária pode possibilitar um alargamento de conceito "investimento público no ensino superior" em comparação ao atual entendimento jurisprudencial que rege a Lei de Responsabilidade Fiscal. Um alargamento que implica criatividade para a obtenção de recursos financeiros extras que permitam às universidades públicas o alcance de seus deveres constitucionais e legais, trabalho que pode ser construído com o auxílio da iniciativa privada, da sociedade civil, e da iniciativa pública, em um cenário de cumprimento às suas obrigações constitucionais.

\section{CONCLUSÃO}

Vários fatores são colocados para a aplicação da Lei de Responsabilidade Fiscal como um limitativo para o investimento na educação superior. $\bigcirc$ próprio Supremo Tribunal Federal abraça uma interpretação restritiva e literal da normatividade, encabeçando a preocupação com uma administração mais retilínea dos recursos públicos, bem como transparente aos olhos dos cidadãos.

Não obstante esse fato, o direito à educação se recobre pelo manto de direito fundamental, fator que não pode ser negligenciado, ainda mais diante do que preconiza a Constituição Federal, de 1988. Diante de elementos externos à sua concretização, deve haver esforço necessário da Administração Pública pela sua implementação.

Observado o limite aposto pela Lei de Responsabilidade Fiscal, destaca-se que a Lei de Diretrizes e Bases da Educação Nacional coloca outras fontes para que as instituições de ensino superior possam ter condições de ofertar cursos, com vagas suficientes, sobejando-se uma inclusão social no ensino superior. A própria autonomia universitária tem se composto no sentido da instrumentalização de elementos para essa inclusão, no sentido de que o investimento seja revertido para a inclusão e qualidade de ensino, embora presente a limitação para gastos por desejo da Administração Pública, e com apoio da Corte Suprema brasileira.

Reverte-se na análise perpetrada o entendimento de que as medidas instrumentais que a autonomia universitária permite não são suficientes. Os dados demonstram essa assertiva, cabendo investimentos privados para a devida atuação dessas instituições, como se observa no exemplo da Universidade Federal da Paraíba. $\bigcirc$ implemento da Emenda Constitucional n 95, aliado à crise econômica e social provocada pela pandemia, apenas deterioraram mais o quadro, destacando- 
-se o posicionamento de que o cumprimento da presente meta do Plano Nacional da Educação (PNE) não será alcançável.

Em virtude dos dados e dos fatos elencados, pode-se enxergar a necessidade de a Administração Pública, em um cenário de compartilhamento entre as unidades federativas, obrigatoriamente, adotar as devidas medidas para que o ensino superior público alcance seus desígnios, chamando-se a esfera privada a compor essa parte responsável, mas com limitações expressas na Constituição Federal, de 1988, no que se refere ao exercício do poder econômico e financeiro. A dignidade da pessoa humana, conforme os ditames da justiça social, deve preponderar.

Ademais, a implementação de políticas públicas merece mais elucidação, como forma criativa de cumprimento ao preceito constitucional, em extravasamento ao quadro limitado de políticas públicas levadas a cabo para o estabelecimento do mister circunscrito. $\bigcirc$ Judiciário, nessa moldura, reconhecendo a flexibilização da aplicação da Lei de Responsabilidade Fiscal, no que concerne à pandemia, conforme manifestação do ministro Alexandre de Moraes, no ${ }^{\circ}{ }^{\circ}$ semestre de 2020, necessita reconhecer a aplicabilidade necessária e imediata dos direitos fundamentais sem limitações infraconstitucionais descabidas, ainda mais quando estas afastam o acesso a tal gama de direitos. A modulação de efeitos necessita ultrapassar o binômio reserva do possível-mínimo existencial, reservando ao dispositivo jurídico aplicação inerente à realização da dignidade da pessoa humana, norma-mandamento imposta pelo documento constitucional.

No último sentido aclamado, fala-se que a técnica interpretativa da ponderação de interesses merece mais intelecção pela maior Corte do País, de forma ao princípio da proporcionalidade buscar adequação do fato à norma. $\bigcirc$ controle de gastos públicos deve se circunscrever a pontos de menos importância na Administração Pública, o que perpassa a própria reforma do Estado. Os direitos sociais e os direitos fundamentais demandam reverência exigida pelo legislador constituinte, devendo a Lei de Responsabilidade Fiscal cumprir sua função com accountability, mas no bojo da dignidade da pessoa humana, a maior luz que deve influenciar sua aplicação. Instrumentos como políticas públicas podem facilitar o acesso ao ensino superior de qualidade; no entanto, a efetiva concreção do acesso se dá com interpretação da Administração Pública e do Judiciário, em consonância com a aplicabilidade imediata das normas fundamentais, cujo conteúdo não pode ser esvaziado no processo ponderativo que rebaixa de degrau os direitos fundamentais e humanos.

\section{REFERÊNCIAS}

AMARAL, Nelson Cardoso. Com a PEC 24I/55 (EC 95) haverá prioridade para cumprir as metas do PNE (20|4-2024)? Revista Brasileira de Educação, Rio de Janeiro, v. 22, n. 71, 2017. 
ANDRÉA, Gianfranco Faggin Mastro; GUNDIM, Wagner Wilson Deiró. Novo Regime Fiscal (EC 95/16) e seus efeitos nas políticas públicas de educação no Brasil. In: REBÊLO, Felipe Cesar José Matos; SOUZA JUNIOR, Arthur Bezerra de; PONÇONI, Maykel. Direitos Sociais Constitucionais: realidade e perspectivas. Londrina: Thoth, 2020.

ARAGÃO, Alexandre Santos de. A autonomia universitária no Estado contemporâneo e no direito positivo brasileiro. Rio de Janeiro: Lumen Juris, 2001 .

BORTOLANZA, Juarez. Trajetória do Ensino Superior Brasileiro: uma busca da origem até a atualidade. XVII Colóquio Internacional de Gestão Universitária. Disponível em: https://repositorio.ufsc.br/bitstream/handle/I 23456789/| 8 I 204/l0 I_00 I 25.pdf?sequence= I \&isAllowed=y. Acesso em: | $4 . \mid$ | . 2020.

BRASIL. Constituição (1988). Constituição da República Federativa do Brasil. Brasília, DF, 5 de outubro de 1988. Disponível em: http://www.planalto.gov.br/ ccivil_03/constituicao/constituicao.htm. Acesso em: 14. I I.2020.

BRASIL. Lei Complementar n. I0I, de 4 de maio de 2000. Estabelece normas de finanças públicas voltadas para a responsabilidade na gestão fiscal e dá outras providências. Brasília, DF, 5 de maio de 2000. Disponível em: http://www.planalto.gov.br/ccivil_03/leis/LCP/Lcp I 0 I.htm. Acesso em: 14. I I.2020.

BRASIL. Supremo Tribunal Federal. Ação Direta de Inconstitucionalidade n. 4.426. Reqte: Associação dos Magistrados Brasileiros - AMB. Intdos: Governador do Estado do Ceará e Assembleia Legislativa do Estado do Ceará. Plenário. Relator Min. Dias Toffoli. Julgamento em 09.02.20 I I. Publicação em Diário de Justiça Eletrônico em: | 8.5.20। I.

DUTRA, Maria de Fátima da Conceição; Renan Moura de Freitas. Os impactos da Emenda Constitucional 95 na Educação Pública. Revista Semana Pedagógica, Recife, v. I, n. I, p. 165-167, 2019.

INSTITUTO BRASILEIRO DE GEOGRAFIA E ESTATÍSTICA. Pesquisa Nacional por Amostra de Domicílios (PNAD) 2012-20I5. Disponível em: https://www. ibge.gov.br/estatisticas/sociais/educacao/9 1 27-pesquisa-nacional-por-amostra-de-domicilios.html?=\&t=o-que-e. Acesso em: 7.9.2020. 
INSTITUTO FEDERAL DO RIO GRANDE DO SUL. Contingenciamento Orçamentário - Diretoria de Administração. 2020. Disponível em:https://firs.edu. br/documentos/. Acesso em: 20.9.2020.

INSTITUTO NACIONAL DE ESTUDOS E PESQUISAS EDUCACIONAIS ANÍSIO TEIXEIRA; MINISTÉRIO DA EDUCAÇÃO. Sinopse Estatística da Educação Superior 20 I8. Brasília: INEP, 20 I9. Disponível em: http://portal.inep.gov.br/censo-da-educacao-superior. Acesso em: 17.7.2020.

JUNQUEIRA, Michelle Asato. Universidade, autonomia e atuação estatal. A avaliação como garantia do direito à educação. 20। I. I48f. Dissertação (Mestrado em Direito Político e Econômico) - Universidade Presbiteriana Mackenzie, São Paulo, 2011.

LEOPOLDO E SILVA, Franklin. Reflexões sobre o conceito e a função da Universidade Pública. Estudos Avançados, São Paulo, n. 42, v. I5, p. 295-304, 200 I.

MINISTÉRIO DA EDUCAÇÃO. Repasses para as Universidades Federais. Disponível em: http://portal.mec.gov.br/images/06.12.20 I 9tab.pdf. Acesso em: 25.8.2020.

MOREIRA NETO, Diogo de Figueiredo. Considerações sobre a Lei de Responsabilidade Fiscal: finanças públicas democráticas. Rio de Janeiro: Renovar, 2001 .

NASCIMENTO, Carlos Valder. Comentários aos arts. $1^{\circ}$ ao 17. In: MARTINS, Ives Gandra Silva; NASCIMENTO, Carlos Valder (Orgs.). Comentários à Lei de Responsabilidade Fiscal. $7^{\circ}$ ed. São Paulo: Saraiva, 2014.

PRESTES, Emília Maria da Trindade; JEZINE, Edineide; SCOCUGLIA, Afonso Celso. Democratização do Ensino Superior Brasileiro: o caso da Universidade Federal da Paraíba. Revista Lusófona de Educação, Lisboa, n. 21, p. 199-218, 2012.

RANIERI, Nina Beatriz Stocco. Autonomia universitária. As universidades públicas e a Constituição Federal de 1988. São Paulo: Editora da Universidade de São Paulo, 1994.

RANIERI, Nina Beatriz Stocco. Autonomia universitária e Lei de Responsabilidade Fiscal: relações e implicações. Revista da Universidade de São Paulo, São Paulo, n. I05, pp. 33-42, abr./maio/jun. 2015. 
SIMÃO, Valdecir Antonio. Gestão universitária da universidade pública frente a Lei de Responsabilidade Fiscal: um estudo exploratório. IV Colóquio Internacional sobre Gestão Universitária na América do Sul. Disponível em: https://repositorio.ufsc.br/xmlui/bitstream/handle/I 23456789/358 I 6/Naldecir\%20Antonio\%20 Sim\%C3\%A30\%20\%20Gest\%C3\%A30\%20universitaria\%20da\%20universidad.pdf?sequence $=4 \&$ isAllowed $=y$. Acesso em: I 4. I I.2020.

SILVA, Adriana Zanini da. O financiamento da educação na Lei de Diretrizes e Bases da Educação Nacional: uma disputa cotidiana. In: RODRIGUES, Isabel Cristina; FREITAS, Aline da Silva; JESUS, Ester Zuzo de. Lei de Diretrizes e Bases da Educação Nacional: estudos em virtude dos 20 anos da Lei n. 9.394/96. São Paulo: LTr, 2017.

SANTOS, Fernando Soares dos. Financiamento Público das Instituições Federais de Ensino Superior - IFES: um estudo da Universidade de Brasília - UnB. 2013. 69f. Dissertação (Mestrado em Economia) - Universidade de Brasília, Brasília, 2013.

UNIVERSIDADE FEDERAL DA PARAÍBA. Relatório de Autoavaliação Institucional. 2010. Disponível em: http://www.proplan.ufpb.br/proplan/contents/documentos/relatorios-de-gestao/relatorio-de-gestao-20 I 0. Acesso em: 20.8.2020. 
回區MS『A ESMAT

FELIPE CESAR JOSÉ MATOS REBÊLO

$192 \begin{aligned} & \text { REVISTA ESMAT } \\ & \text { ANO } 13-\text { No } 21 \\ & \text { Pags } 167-192 \\ & \mathbf{I} \text { NAN. A AuN. } 2021\end{aligned}$ 